\title{
Clinical features and preventive therapies of radiation-induced xerostomia in head and neck cancer patient: a literature review
}

\author{
Graziella Chagas Jaguar*, José Divaldo Prado, Daniel Campanhã and Fábio Abreu Alves
}

\begin{abstract}
Xerostomia or dry mouth is one of the most common and disturbing adverse effects following radiotherapy for head and neck cancer (HNC). This complication strongly increases the risk for dental caries, difficulties with chewing, swallowing and sleep disorders with significant impact on patients' quality of life. Current treatment approaches of xerostomia are often difficult and bring in many cases no substantial relief for the patient. This paper discusses the clinical features and current knowledge of xerostomia prevention in order to evaluate the real possibilities of reducing the incidence and severity of this complication in HNC patients. Salivary gland cytoprotectants (amifostine), muscarinic agonist stimulation (pilocarpine and bethanechol), salivary gland-sparing radiation technique (intensity-modulated radiotherapy- IMRT), surgical relocation of the submandibular gland, intraoral stent and stem cell transplantation are promising techniques that are discussed in this study.
\end{abstract}

Keywords: Head and neck, Radiotherapy, Xerostomia, Salivary glands, Prevention

\section{Background}

Radiotherapy (RT) plays a major role in the curative treatment of $\mathrm{HNC}$, either as single-modality therapy or in combination with chemotherapy, surgery, or both [1-3]. Despite the more advanced methods of delivery, such as IMRT, the major salivary glands are often irradiated due to the proximity of primary tumors and lymph nodes $[4,5]$ with several secondary effects that represent a challenge to multidisciplinary teams [6].

Xerostomia or dry mouth is the most common and prominent symptom complication during and after HNC radiotherapy as a result of salivary gland damage $[5,7]$. Approximately $70 \%$ of patients receiving HNC radiotherapy develop hyposalivation with significant alteration in volume, consistency and $\mathrm{pH}$ of secreted saliva [5]. Due to saliva quantitative and qualitative changes, patients become more vulnerable to oral and dental diseases with important impairment in quality of life $[5,8]$. Xerostomia may persist for 6 months to several years after RT. The severity of the damage is depending on the salivary function before treatment, the

\footnotetext{
* Correspondence: graziellajaguar@gmail.com

Departamento de Estomatologia, AC Camargo Cancer Center, R: Prof.

Antônio Prudente, 211 Bairro Liberdade, São Paulo, SP 01509-900, Brazil
}

area of salivary tissue exposed, the total dose radiation and response of each individual $[9,10]$.

Literature data regarding xerostomia prevention is still undefined and conflicting results have been shown $[2,8,11,12]$. Several therapies with different protocols such as cytoprotectants (amifostine), IMRT, cholinergic stimulants, surgical submandibular gland transfer, intraoral stent and stem cell therapies have been targeted against xerostomia. Despite these, there is little substantive improvement in the ability to prevent this complication. The aim of this study was to review current knowledge concerning xerostomia in order to discuss the real perspectives on reducing the incidence and severity of this complication.

\section{Materials and methods}

The authors performed a commented Literature revision through a search of PubMed and MEDLINE electronic databases for the following keywords: Head and neck, Radiotherapy, Xerostomia, Salivary glands and prevention. The research was restricted from 1991 to 2016. 


\section{Radiation-induced xerostomia}

Radiation-induced xerostomia has been reported in the first days of RT, with dose between 2 and 10 Gy in the cervico-facial fields [13]. Clinically, an increase in salivary viscosity has been observed with important impact on the processes of speech, mastication, formation of food bolus and swallowing [9], (Fig. 1). In addition, xerostomia increases the risk of oral infections such as candidosis, mucositis, caries, periodontal disease and osteoradionecrosis $[14,12]$.

There are several ways of recording salivary gland damage [8]. Measurements of salivary flow rate are the most commonly applied objective measures of hyposalivation [15]. Imaging techniques, such as salivary gland scintigraphy can also be used to evaluate salivary gland dysfunction $[8,16]$. However, because xerostomia is defined as a symptom, it is equally important to estimate the subjective appreciation of oral dryness by the patient $[15,16]$. Recent evidence suggests that patient self-reported scores, rather than physician-assessed scores, should be the main end points in evaluating xerostomia [16].

The exact mechanism of the acute radiation-induced salivary gland damage is an enigma. Salivary glands are highly differentiated and slowly dividing tissue and therefore are expected to be relatively radioresistant [17-19]. It is suggested that early damage may be due to damage to the signal transduction system plasma membrane of acinar cells, compromising the receptor-mediated signaling pathways of water excretion $[19,20]$. No immediate cell death takes place. Late xerostomia, on the other hand, may be explained by the damage to the salivary gland stem cells and subsequent lack of proper cell renewal [21, 22].

\section{Xerostomia prevention therapies Amifostine}

Amifostine is an organic thiophosphate that is able to protect cells from radiation damage by scavenging

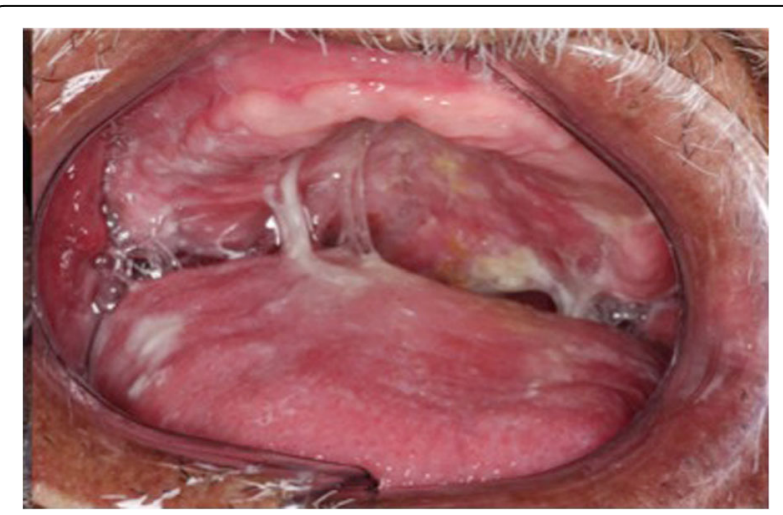

Fig. 1 Patient with acute Xerostomia showing an increase in salivary viscosity with important impact on the processes of speech, mastication, formation of food bolus and swallowing oxygen-derived free radicals. Despite being the only drug approved by FDA (Food and Drugs Association) for radioprotection against xerostomia, the use of amifostine is highly controversial because of its toxicity, compromised tumor control and cost [22].

Wasserman et al. [23] evaluated 303 HNC patients who underwent RT in an open-label phase III trial. The patients were divided into 2 arms: Control $(n=150)$ and Amifostine $(n=150)$. The amifostine arm received (200 $\mathrm{mg} / \mathrm{m}^{2}$ intravenous) $15-30 \mathrm{~min}$ before each fraction of RT. Amifostine administration showed a reduced incidence of Grade 2 xerostomia over 2 years of followup $(p=0.002)$, increase the unstimulated saliva volume $(p=0.011)$ and improved oral comfort $(<0.001)$. Loco regional control rate, progression-free survival and overall survival were not significantly different between the groups. Similar results have previously been demonstrated in the Brizel et al. [24] study, in which amifostine significantly reduced the incidence of grade 2 acute xerostomia from $78 \%$ to $51 \%$ and reduced the incidence of grade 3 chronic xerostomia from $57 \%$ to $34 \%$ without altering disease control or survival. However, severe toxicity was an important issue reported in this trial. Nausea, vomiting, hypotension and allergic reactions were the most common side effects. Fifty-three percent of the patients receiving amifostine had at least one episode of nausea and/or vomiting.

In a study conducted by Rades et al. [25], 39 patients, who received intravenous amifostine, were evaluated. Of these patients, 16 (41\%) had severe toxicity, especially hypotension (11 patients), vomiting (10 patients) and allergic reaction (8 patients). Adverse effects resulted in discontinuation of RT for 1 to 3 days in 4 patients. These authors stated that daily intravenous amifostine was associated with a high rate of serious adverse effects leading to discontinuation of the drug and sometimes delay in RT. Recent studies, however, have demonstrated that subcutaneous administration of amifostine was as effective as intravenous administration and safer considering toxicity [26, 27]. Further research on the benefits of using subcutaneous amifostine is still required.

\section{Systemic sialogogues}

The prophylactic use of systemic sialogogues for radiationinduced xerostomia is widely reported in the literature [28-36]. These drugs are defined as systemic stimulants of salivary gland function by acting directly on the parasympathetic nervous system [19]. With regard to salivary glands, the response to stimulus is dependent on the remaining number of functional acinar cells [37]. Among several systemic sialogogues reported in the literature, this article reviewed the preventive effect of Pilocarpine and Bethanechol. 


\section{Pilocarpine hydrochloride}

Pilocarpine hydrochloride is the most widely studied sialogogue in the literature $[28,29,31,34,35]$. It is defined as a cholinergic parasympathomimetic agent with action on muscarinic and $\alpha / \beta$-adrenergic receptors $[17,38]$.

The protective effect of pilocarpine on salivary glands remains unclear. Some authors state that it is pharmacological mediator, with pilocarpine being able to cause depletion of secretory granules in serous cells and consequently decrease radiation-induced salivary damage [17, 28, 29]. Others postulated that pre-treatment with pilocarpine leads to an activation of intracellular signaling pathways [20].

The study conducted by Valdez et al. [28] was the first randomized double blind clinical trial that evaluated the use of pilocarpine during the course of RT. A total of 9 patients with HNC took either pilocarpine or placebo four times daily for 3 months, beginning the day before RT. The pilocarpine group reported a lower frequency of oral symptoms during RT than the placebo group $(p<0.0001)$. Similar findings were demonstrated by Zimmerman et al. [29], who retrospectively compared the subjective post-irradiation scores of patients who received concomitant oral pilocarpine during RT $(n=17)$ with those of similar cohorts who did not receive pilocarpine $(n=18)$. The concomitant pilocarpine group received $5 \mathrm{mg}$ pilocarpine four times daily beginning on the first day of RT and continuing for 3 months after completion of treatment. It was observed that patients who used pilocarpine showed significantly less subjective xerostomia in comparison with a similar cohort of patients without the drug.

In a recent systematic review, Yang et al. [39] evaluated 6 prospective, randomized and controlled trials studying the effect of concomitant administration of pilocarpine for radiation-induced xerostomia. The total number of patients was 369 in the pilocarpine group and 367 in control group. The authors showed that concomitant pilocarpine increases unstimulated salivary flow rate and reduces clinician-rated xerostomia grade after radiation. It also relives patients' xerostomia at 6 months and the adverse effects were mild and tolerable.

\section{Bethanechol chloride}

This cholinergic agonist is a carbamic ester of $\beta$ methylcholine and is an analogue of acetylcholine. However, in contrast to acetylcholine, bethanechol is resistant to destruction by cholinesterases, which results in more prolonged effects. It shows a similar mechanism of action to pilocarpine, stimulating the parasympathetic nervous system [40]. However, it seems to act more specifically, mainly on the muscarinic receptors, not activating the $\alpha / \beta$-adrenergic receptors, as pilocarpine does. Bethanechol is currently indicated for the treatment of postoperative and postpartum urinary retention [41]. It is contraindicated in patients with bronchial asthma, peptic ulcer, hyperthyroidism, pronounced bradycardia, hypotension, patients with coronary artery disease, epilepsy or Parkinson's disease. Adverse effects are rare after oral administration and are dose related [33].

A study conducted by Jham et al. [40] was the first to evaluate the use of bethanechol concomitant to RT, as a method of preventing xerostomia. These authors studied 55 patients who underwent external beam conventional RT with minimum dose of $45 \mathrm{~Gy}$ in one or more major salivary glands. Patients were randomly allocated into oral bethanechol (liberan $\left.{ }^{\circ}\right) 25 \mathrm{mg}$, three times a day (Group 1) or artificial saliva (OralBalance ${ }^{\circ}$ ) (Group 2). Bethanechol was administered with irradiation and used until the end of treatment. A significantly high increase in whole resting saliva was observed immediately after RT $(p=0.03)$ in patients who had received bethanechol. They suggest that the use of bethanechol during RT for HNC is associated with favorable results and it has minimal side effects. However, it was also emphasized that further studies were necessary, comparing bethanechol and pilocarpine in larger samples, in order to determine which drug provided the best cost/benefit ratio.

Our group, in Jaguar et al. study [36], assessed the prophylactic bethanechol effect in a prospective doubleblind setting in order to reduce or ameliorate xerostomia and hyposalivation. A total of 97 head and neck cancer patients were allocated into two groups: Bethanechol $(n=48)$ or Placebo $(n=49)$. The patients took either Bethanechol or Placebo ( $25 \mathrm{mg}$ tablets) twice a day from the beginning of radiotherapy to 1 month after the treatment. Bethanechol group presented significantly lower xerostomia scores when compared with Placebo group $(p<0.001)$. Bethanechol therapy also increased the unstimulated/stimulated whole saliva and the mean uptake/ excretion rates of the salivary glands $(p<0.050)$. The authors suggest that prophylactic use of bethanechol during radiotherapy was found to be effective in decreasing the salivary gland damage with important impact on xerostomia complaint with minimal adverse effect.

\section{Intensity modulated radiation therapy (imrt)}

IMRT represents an advanced form of tridimensional conformal RT. With this techinique, part of major salivary glands can be spared from the irradiation field particularly contralateral salivary gland with impact in decrease xerostomia [42, 43]. Several clinical studies using IMRT assessed the dose constraints for salivary gland; however, the literature still shows conflicting results. In the Eisbruch et al. [42] study, the parotid gland that received a mean dose $\leq 26 \mathrm{~Gy}$, recovered the pretreatment salivary production levels one year after RT. Whereas, Chao et al. [44] suggest a mean dose of 32Gy 
in $50 \%$ of the parotid gland volume to recover the salivary output. It is known that after a dose exceeding 52Gy, there is permanent salivary damage [8]. The consensus has been reached that xerostomia can be substantially reduced by limiting the maximum mean dose threshold to 26 Gy for at least one parotid gland.

In spite of technical improvements, about $40 \%$ of patients still suffer from symptoms after IMRT [45]. The main difference with this parotid gland-sparing RT is in partial recovery over time. The damaged parotid gland is capable of regaining some of its function in the first 2 years after IMRT, differently of conventional radiotherapy, which results in persistent xerostomia [45, 46]. Recent researches have documented the existence of stem/progenitor cells in the salivary gland [21, 46-49]. There is evidence that these cells are capable of proliferation, differentiation and also regenerating damaged tissue. Recovery after RT appears to be dependent on the number of remaining stem cells after treatment [49]. LuijK et al. [46] showed that in mice, rats, and humans, stem and progenitor cells reside in the region of the parotid gland containing the major ducts. The inclusion of the ducts in the radiation field led to loss of regenerative capacity, resulting in long-term gland dysfunction with reduced saliva production. These authors suggest that the radiation dose to the region responsible for functional recovery could be reduced substantially using IMRT, with impact in xerostomia prevention.

Over the past 10 years, an increasing number of data has demonstrated the importance of sparing also the submandibular gland from the radiation field, confirming the role of these glands in the patient's subjective sense of moisture $[43,50]$. Mean radiation doses to the submandibular gland exceeding 39 Gy cause permanent ablation of both stimulated and unstimulated flow [50]. Saarilahti et al. [51] investigated a total of $36 \mathrm{HNC}$ patients with a mean follow-up of 12 months. All patients had at least one parotid gland excluded from the planned target volume (receiving maximum dose of $25 \mathrm{~Gy}$ ) and 18 out of 36 patients receiving a mean dose between 20 and 25 Gy had the contralateral submandibular gland spared. It was observed that 12 months after IMRT, the mean of unstimulated saliva flow was $60 \%$ of the baseline value among patients who had one submandibular spared versus $25 \%$ among those who did not $(p=0.006)$. Furthermore, a significant reduction in xerostomia complaint was noted in patients whose contralateral submandibular was spared $(p=0,018)$, and they used fewer saliva substitutes. These authors suggested that submandibular gland sparing by means of IMRT is effective in the prevention of radiationassociated xerostomia.

Despite the submandibular gland-sparing IMRT being considered an effective method to reduce the risk of xerostomia in $\mathrm{HNC}$ patients, a potential disadvantage is the possible loco regional recurrence at the site of the spared gland [52]. Because of this, it must be indicated in selected patients so that tumor control is not compromised.

\section{Submandibular gland transplantation}

This method was described by Seikaly and Jha in 1999 as a procedure of transferring the contralateral submandibular salivary gland to the submental space outside the proposed radiation field, before starting RT. These authors demonstrated that this surgical procedure is safe, quick, easy, cost effective and a feasible approach to preventing xerostomia. It is based on retrograde flow through the facial vessels. The submandibular gland is released from surrounding structures and then repositioned in the submental space over the anterior belly of the digastric muscle and the border is marked with gauge wire to help identify the gland during RT planning [53].

Jha et al. [53] conducted a prospective clinical trial with $15 \mathrm{HNC}$ patients who had the submandibular gland transferred to the submental space before RT. It was observed that all salivary glands were functional postsurgery and the patients did not complain of any xerostomia in a follow-up of 1 month after RT. These authors showed that surgical submandibular gland transfer preserves its function and prevents the development of radiation-induced xerostomia. Similar results were found by Jha et al. [54], who evaluated $43 \mathrm{HNC}$ patients who underwent submandibular salivary gland transfer following RT. The median follow up was 14 months. These authors observed that $81 \%$ of the patients had no or minimal xerostomia and $19 \%$ developed moderate to severe xerostomia.

In 2004, Pathak et al. [55] compared the salivary output during rest, of patients with transferred and untransferred submandibular glands before and after RT. Baseline salivary outputs of both submandibular glands showed no significant difference. However, after radiation therapy, $73 \%$ of the mean salivary rate in transferred gland was preserved, while only $27 \%$ was preserved in the untransferred gland $(p=0.000)$.

A systematic review, conducted by Sood et al. [56], evaluated in seven articles the efficacy of salivary gland transfer in prevention of xerostomia and maintenance of salivary flow rate after radiation therapy. In a total of 177 patients at mean follow-up of 22.7 months, submandibular transfer prevented xerostomia in $82.7 \%$ of patients and twelve months after treatment, unstimulated and stimulated salivary flow rates rose to $88 \%$ and $76 \%$ of baseline values, respectively.

This technique has been successfully demonstrated as the potential approach to preserving salivary function and prevents radiation-induced xerostomia in HNC 
patients [54-56]. However, all authors are unanimous with regard to the patient selection and eligibility criteria (squamous cell carcinoma of the larynx, oropharynx or hypopharynx; clinical and radiologic absence of contralateral neck nodes and expected survival $\geq 1$ year).

\section{Intraoral stent}

The intraoral stent is an individualized mouth-opening device, which may be used during HNC RT with the intention of preventing unnecessary irradiation in normal adjacent tissue $[57,58]$. Several benefits have been described for the use of this device: It increases the distance between the mandible and the maxilla, focusing the radiation dose more precisely on the target volume, and immobilize the mandible (Fig. 2a,b). Besides, its production is safe, easy to fabricate and comfortable to wear [58-60]. Recent studies have investigated the use of this device with the intention of minimizing the adverse effects of radiation, including osteoradionecrosis, oral mucositis and xerostomia [57-61].

In 2013, our group at AC Camargo Cancer Center was the first to conduct a dosimetric study [57] in a patient with squamous cell carcinoma of the tongue who underwent IMRT, comparing the tomography computer preirradiation planning with and without the use of the intraoral stent. This study showed that the area of the maxillary teeth, hard palate, both parotid glands and the left submandibular gland were more preserved from the radiation dose with the use of the device than without it, with no effect on the target structure. Interestingly, after 6 months of RT, the patient reported an improvement in xerostomia severity, probably a resulted of the lower radiation dose in both parotid and submandibular glands, due to depressing the mandible.

In 2014, another study [58] conducted for our group evaluated the real benefit of intraoral stent in 33 patients with tongue or floor of the mouth cancer who underwent IMRT in a retrospective setting. The patients were divided into two groups: group 1 (with stent, $n=19$ ) and group 2 (without stent, $n=14$ ). The mean dose in maxilla was significantly lower in group 1 (20.9Gy) than in group 2 (35.8Gy) $(p=0.05)$. The mean dose in ipsilateral parotid was $35.0 \mathrm{~Gy}$ in group 1 versus $41.8 \mathrm{~Gy}$ in group $2(p=0.05)$. The authors concluded that the use of this device, in combination with IMRT, reduces even more the radiation dose in the glandular tissue with possible impact in salivary changes.

A study conducted by Goel et al. [61] was the first prospective trial to evaluate the efficacy of positioning stents in order to minimize the potential clinical effects of conventional external beam radiation on oral tissues. Patients with tongue cancer were allocated into a study group $352(n=24)$, where the patients wore intraoral stents during RT, and into a control group $(n=24)$. The radiation side effects were assessed over a period of 60 days from the beginning of RT. The use of intraoral stent during RT for tongue cancer was associated with significantly lower occurrence of mucositis $(p<0.01)$, xerostomia $(p=0.06)$ and salivary changes $(p=0.039)$ compared to the control group. These authors stated that the lower occurrence of mucositis and xerostomia probably resulted from the exclusion of the maxilla and the parotid glands from the radiation field by depressing the mandible with the positioning stent.

The exact indication for the use of intraoral-stents is still controversial. Some authors indicate their use only during tongue cancer radiation therapy [59-61]; whereas others show them to be of benefit in tumors located in the floor of the mouth [58] and nasopharyngeal [62]. In Verrone et al. [58] opinion, this device must be referred to in all tumor cases that present healthy contralateral structures (maxilla or mandible) that need to be spared from dose irradiation with no reduced effect in the prescribed dose to the target volume. Long-term prospective studies are needed to evaluate not only the real indication of this device but also the benefits from other radiation techniques.

\section{Stem cell transplantation}

New insights into the autologous transductal stem cell transplantation have been documented as a viable xerostomia prevention strategy in HNC patients. Since 2004, several animal models studies were performed in which healthy submandibular and parotid gland stem cells were

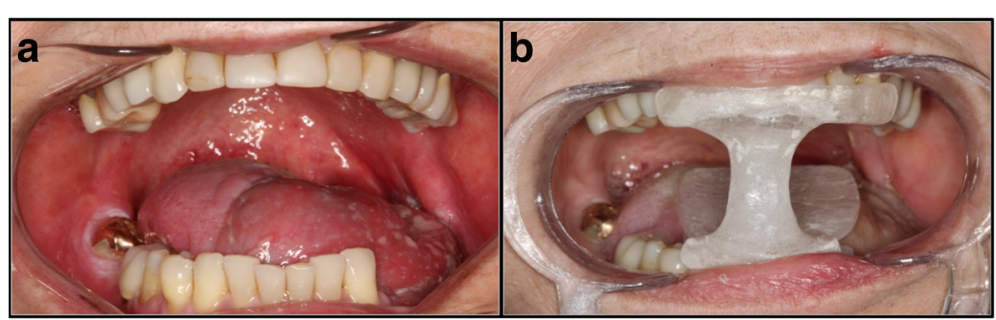

Fig. 2 a Clinical presentation of 674 the oral suqamous carcinoma involving the tongue after partial glossectomy. b Clinical presentation of the patient wearing the intraoral stent. The device incresed the distance between the maxilla and mandible, depressed the tongue, and stabilized the mandible 
collected prior to irradiation. These studies showed that the stem cells are capable to regenerate the function of the salivary gland by differentiation of these transplanted stem cells into functional salivary gland cells [43, 46, 48, 49]. These authors indicate that in the near future, these cells may have the potential to reduce xerostomia and hiposalivation.

\section{AC camargo cancer center protocol for xerostomia prevention}

As part of the AC Camargo Cancer Center's protocol, all patients with head and neck tumors who will be submitted to RT is referred to Stomatology Department in order to prevent or minimize the radiation oral adverse effects. Based on our experience and published researches $[36,57,58]$, we could establish a xerostomia prevention protocol, as follow:

- We indicated the use of bethanechol (25 mg tablets) twice a day $(12 / 12 \mathrm{~h})$ from the beginning of radiotherapy to 1 month after the treatment. It is essential to observe that patients with bronchial asthma, peptic ulcer, hyperthyroidism, pronounced bradycardia, hypotension, coronary artery disease, epilepsy or Parkinson's disease are contraindicated.

- The use of intraoral stent during all RT sections with the intention of preventing unnecessary irradiation in the salivary glands due to depressing the mandible.

\section{Conclusion}

The solution to xerostomia may not reside in a single approach but rather in the use of a combination of agents. Further trials should focus efforts on the association of submandibular gland sparing and protection against radiation such as IMRT, intraoral stent and the use of preventive sialogogues.

\section{Abbreviations}

FDA: Food and Drugs Association; Gy: Grey; HNC: Head and Neck Cancer; IMRT: Intensity Modulated Radiation Therapy; RT: Radiotherapy

\section{Acknowledgements}

The authors would like to acknowledge Emanuella Correa for her assistance in editing the manuscript and her invaluable guidance.

\section{Funding}

Currently, we don't have any funding.

\section{Availability of data and materials}

It is Review Article.

\section{Authors' contributions}

GJ carried out the design of the study and performed the acquisition of data. JP conceived of the study and participated in its design. FA helped to draft the manuscript and coordination. All authors read and approved the final manuscript.
Ethics approval and consent to participate

Not applicable as it is Review article.

\section{Consent for publication}

Not applicable as it is Review article.

Competing interests

The authors declare that they have no competing interests.

\section{Publisher's Note}

Springer Nature remains neutral with regard to jurisdictional claims in published maps and institutional affiliations.

Received: 24 March 2017 Accepted: 5 July 2017

Published online: 15 August 2017

\section{References}

1. Nevens $D$, Nuyts $S$. The role of stem cells in the prevention and treatment of radiation-induced xerostomia in patients with head and neck cancer. Cancer Med. 2016;5:1147-53.

2. Jensen DH, Oliveri RS, Trojahn Kølle SF, Fischer-Nielsen A, Specht L, et al. Mesenchymal stem cell therapy for salivary gland dysfunction and xerostomia: a systematic review of preclinical studies. Oral Surg Oral Med Oral Pathol Oral Radiol. 2014;117:335-42.

3. Vissink A, Jansma J, Spijkervet FK, Burlage FR, Coppes RP. Oral sequelae of head and neck radiotherapy. Crit Rev Oral Biol Med. 2003;14:199-212.

4. Bhide SA, Ahmed M, Newbold K, Harrington K, Nutting CM. The role of intensity modulated radiotherapy in advanced oral cavity carcinoma. J Cancer Res Ther. 2012:8:67-71.

5. Acauan MD, Figueiredo MA, Cherubini K, Gomes AP, Salum FG Radiotherapy-induced salivary dysfunction: Structural changes, pathogenetic mechanisms and therapies. Arch Oral Biol. 2015;60:1802-10.

6. Koga DH, Salvajoli JV, Kowalski LP, Nishimoto IN, Alves FA. Dental extractions related to head and neck radiotherapy: ten-year experience of a single institution. Oral Surg Oral Med Oral Pathol Oral Radiol Endod. 2008:105:1-6.

7. Wang X, Eisbruch A. IMRT for head and neck cancer: reducing xerostomia and dysphagia. J Radiat Res. 2016;57:69-75.

8. Jensen SB, Pedersen AM, Reibel J, Nauntofte B. Xerostomia and hypofunction of the salivary glands in cancer therapy. Support Care Cancer. 2003;11:207-25

9. Deasy JO, Moiseenko V, Marks L, Chao KS, Nam J, et al. Radiotherapy dosevolume effects on salivary gland function. Int J Radiat Oncol Biol Phys. 2010; 76:58-63.

10. Eisbruch A, Ten Haken RK, Kim HM, Marsh LH, Ship JA. Dose, volume, and function relationships in parotid salivary glands following conformal and intensity-modulated irradiation of head and neck cancer. Int J Radiat Oncol Biol Phys. 1999:45:577-87.

11. Kałużny J, Wierzbicka M, Nogala H, Milecki P, Kopeć T. Radiotherapy induced xerostomia: mechanisms, diagnostics, prevention and treatment-evidence based up to 2013. Otolaryngol Pol. 2014;68:1-14.

12. Jensen $S B$, Pedersen AM, Vissink A, Andersen E, Brown CG, et al. A systematic review of salivary gland hypofunction and xerostomia induced by cancer therapies: management strategies and economic impact. Support Care Cancer. 2010;18:1061-79.

13. Leek $\mathrm{H}$, Albertsson M. Pilocarpine treatment of xerostomia in head and neck patients. Mícron. 2002;33:153-5.

14. Vissink A, van Luijk P, Langendijk JA, Coppes RP. Current ideas to reduce or salvage radiation damage to salivary glands. Oral Dis. 2015;21:1-10.

15. Dirix $\mathrm{P}$, Nuyts $\mathrm{S}$, Vander Poorten $\mathrm{V}$, Delaere $\mathrm{P}$, Van den Bogaert $\mathrm{W}$. The influence of xerostomia after radiotherapy on quality of life: results of a questionnaire in head and neck cancer. Support Care Cancer. 2008:16:171-9.

16. Meirovitz A, Murdoch-Kinch CA, Schipper M, Pan C, Eisbruch A. Grading xerostomia by physicians or by patients after intensity-modulated radiotherapy of head-and-neck cancer. Int J Radiat Oncol Biol Phys. 2006:66:445-53.

17. Coppes RP, Vissink A, Zeilstra LJ, Konings AW. Muscarinic receptor stimulation increases tolerance of rat salivary gland function to radiation damage. Int J Radiat Biol. 1997;5:615-25. 
18. Nagler RM. The enigmatic mechanism of irradiation-induced damage to the major salivary glands. Oral Dis. 2002;3:141-6.

19. Coppes RP, Zeilstra LJW, Kapinga HH, Konings AWT. Early to late sparing of radiation damage to the parotid gland by adrenergic and muscarinic receptor agonists. Br J Cancer. 2001;85:1055-63.

20. Konings AW, Coppes RP, Vissink A. On the mechanism of salivary gland radiosensitivity. Int J Radiat Oncol Biol Phys. 2005;4:1187-94.

21. Nanduri LS, Maimets M, Pringle SA, van der Zwaag M, van Os RP, et al Regeneration of irradiated salivary glands with stem cell marker expressing cells. Radiother Oncol. 2011;99:367-72

22. Berk LB, Shivnani AT, Small W Jr. Pathophysiology and management of radiation-induced xerostomia. J Support Oncol. 2005;3:191-200.

23. Wasserman TH, Brizel DM, Henke M, Monnier A, Eschwege F, et al Influence of intravenous amifostine on xerostomia, tumor control, and survival after radiotherapy for head and neck cancer: 2 year follow-up of a prospective, randomized, phase III trial. Int J Radiat Oncol Biol Phys. 2005;63:985-90

24. Brizel DM, Overgaard J. Does amifostine have a role in chemoradiation treatment? Lancet Oncol. 2003:4:378-81.

25. Rades D, Fehlauer F, Bajrovic A, Mahlmann B, Richter E, et al. Serious adverse effects of amifostine during radiotherapy in head and neck cancer patients. Radiother Oncol. 2004;70:261-4.

26. Haddad R, Sonis S, Posner M, Wirth L, Costello R, et al. Randomized phase 2 study of concomitant chemoradiotherapy using weekly carboplatin/ paclitaxel with or without daily subcutaneous amifostine in patients with locally advanced head and neck cancer. Cancer. 2009;115:4514-23.

27. Gu J, Zhu S, Li X, Wu H, Li Y, et al. Effect of amifostine in head and neck cancer patients treated with radiotherapy: a systematic review and meta-analysis based on randomized controlled trials. PLoS One. 2014;9:95968.

28. Valdez $\mathrm{H}$, Wolff A, Atkinson JC, Macynski AA, Fox PC. Use of pilocarpine during head and neck radiation therapy to reduce xerostomia and salivary dysfunction. Cancer. 1993;71:1848-51.

29. Zimmerman RP, Mark RJ, Tran LM, Juillard GF. Concomitant pilocarpine during head and neck irradiation is associated with decreased posttreatment xerostomia. Int J Radiat Oncol Biol Phys. 1997:3:571-5

30. Lajtman Z, Krajina Z, Krpan D, Vincelj J, Borcić V, et al. Pilocarpine in the prevention of postirradiation xerostomia. Acta Med Croatica. 2000;54:65-7.

31. Haddad P, Karimi M. A randomized, double-blind, placebo-controlled trial of concomitant pilocarpine with head and neck irradiation for prevention of radiation-induced xerostomia. Radiother Oncol. 2002;1:29-32.

32. Warde P, O'Sullivan B, Aslanidis J, et al. A Phase III placebo-controlled trial of oral pilocarpine in patients undergoing radiotherapy for head-and-neck cancer. Int J Radiat Oncol Biol Phys. 2002;54:9-13.

33. Gornitsky M, Shenouda G, Sultanem K, Katz H, Hier M, et al. Doubleblind randomized, placebo-controlled study of pilocarpine to salvage salivary gland function during radiotherapy of patients with head and neck cancer. Oral Surg Oral Med Oral Pathol Oral Radiol Endod. 2004; 98:45-52.

34. Scarantino C, LeVeque F, Swann RS, White R, Schulsinger A, et al. Effect of pilocarpine during radiation therapy: results of RTOG 97-09, a phase III randomized study in head and neck câncer patients. J Support Oncol. 2006;4:252-8.

35. Burlage FR, Roesink JM, Faber H, Vissink A, Langendijk JA, et al. Optimum dose range for the amelioration of long term radiation-induced hyposalivation using prophylactic pilocarpine treatment. Radiother Oncol. 2008;86:347-53.

36. Jaguar GC, Lima EN, Kowalski LP, Pellizzon AC, Carvalho AL, et al. Double blind randomized prospective trial of bethanechol in the prevention of radiation-induced salivary gland dysfunction in head and neck cancer patients. Radiother Oncol. 2015;115:253-6.

37. Roesink JM, Moerland MA, Hoekstra A, Van Rijk PP, Terhaard CH. Scintigraphic assessment of early and late parotid gland function after radiotherapy for head and neck cancer: a prospective study of dosevolume response relationships. Int J Radiati Oncol Biol Phys. 2004;5: $1451-60$.

38. Fox PC, Atkinson JC, Macynski AA, Wolff A, Kung DS, et al. Pilocarpine treatment of salivary gland hyposalivation and dry mouth (xerostomia). Arch Intern Med. 1991;6:1149-52.
39. Yang WF, Liao GQ, Hakim SG, Ouyang DQ, Ringash J, et al. Is Pilocarpine Effective in Preventing Radiation-Induced Xerostomia? A Systematic Review and Meta-analysis. Int J Radiat Oncol Biol Phys. 2016;94:503-11.

40. Jham BC, Teixeira IV, Aboud CG, Carvalho AL, Coelho Mde M, et al. A randomized phase III prospective trial of bethanechol to prevent radiotherapy-induced salivary gland damage in patients with head and neck cancer. Oral Oncol. 2007:43:137-42.

41. Epstein JB, Burchell JL, Emerton S, Le ND, Silverman S Jr. A clinical trial of bethanechol in patients with xerostomia after radiation therapy. A pilot study. Oral Surg Oral Med Oral Pathol. 1994;6:610-4.

42. Eisbruch A, Kim HM, Terrell JE, Marsh LH, Dawson LA, et al. Xerostomia and its predictors following parotid-sparing irradiation of head-and-neck cancer. Int J Radiat Oncol Biol Phys. 2001;3:695-704.

43. Dirix P, Vanstraelen B, Jorissen M, Vander Poorten V, Nuyts S. Intensitymodulated radiotherapy for sinonasal cancer: improved outcome compared to conventional radiotherapy. Int J Radiat Oncol Biol Phys. 2010;15:998-1004.

44. Chao KS, Deasy JO, Markman J, Haynie J, Perez CA, et al. A prospective study of salivary function sparing in patients with head-and-neck cancers receiving intensity-modulated or three-dimensional radiation therapy: initial results. Int J Radiat Oncol Biol Phys. 2001:4:907-16

45. Nutting CM, Morden JP, Harrington KJ, Urbano TG, Bhide SA, et al. Parotidsparing intensity modulated versus conventional radiotherapy in head and neck cancer(PARSPORT): a phase 3 multicentre randomised controlled trial. Lancet Oncol. 2011;12:127-36.

46. Van Luijk P, Pringle S, Deasy JO, Moiseenko W, Faber H, et al. Sparing the region of the salivary gland containing stem cells preserves saliva production after radiotherapy for head and neck cancer. Sci Transl Med. 2015;16:305.

47. Feng J, Van der Zwaag M, Stokman MA, Van Os R, Coppes RP. Isolation and characterization of human salivary gland cells for stem cell transplantation to reduce radiation-induced hyposalivation. Radiother Oncol. 2009;92:466-71.

48. Coppes RP, Stokman MA. Stem cells and the repair of radiation-induced salivary gland damage. Oral Dis. 2011;17:143-53.

49. Lombaert IM, Brunsting JF, Wierenga PK, Faber H, Stokman MA, et al. Rescue of salivary gland function after stem cell transplantation in irradiated glands. PLoS One. 2008;3:2063.

50. Mendenhall WM, Mendenhall CM, Mendenhall NP. Submandibular glandsparing intensity-modulated radiotherapy. Am J Clin Oncol. 2014;37:514-6.

51. Saarilahti K, Kouri M, Collan J, et al. Sparing of the submandibular glands by intensity modulated radiotherapy in the treatment of head and neck cancer. Radiother Oncol. 2006;78:270-5.

52. Bussels B, Maes A, Hermans R, Nuyts S, Weltens C, et al. Recurrences after conformal parotid-sparing radiotherapy for head and neck cancer. Radiother Oncol. 2004:72:119-27.

53. Jha N, Seikaly H, McGaw T, Coulter L. Submandibular salivary gland transfer prevents radiation-induced xerostomia. Int J Radiat Oncol Biol Phys. 2000;1:7-11.

54. Jha N, Seikaly H, Harris J, Williams D, Liu R, et al. Prevention of radiation induced xerostomia by surgical transfer of submandibular salivary gland into the submental space. Radiother Oncol. 2003:66:283-9.

55. Pathak KA, Bhalavat RL, Mistry RC, Deshpande MS, Bhalla V, et al. Upfront submandibular salivary gland transfer in pharyngeal cancers. Oral Oncol. 2004;40:960-3

56. Sood AJ, Fox NF, O'Connell BP, Lovelace TL, Nguyen SA, et al. Salivary gland transfer to prevent radiation-induced xerostomia: a systematic review and meta-analysis. Oral Oncol. 2014;50:77-83.

57. Verrone JR, Alves FA, Prado JD, Boccaletti KW, Sereno MP, Silva ML, et al. Impact of intraoral stent on the side effects of radiotherapy for oral cancer. Head Neck. 2013;35:213-7.

58. Verrone JR, Alves FA, Prado JD, Marcicano AD, de Assis Pellizzon AC, Damascena AS, Jaguar GC. Benefits of an 649 intraoral stent in decreasing the irradiation dose to oral healthy tissue: dosimetric and clinical features. Oral Surg Oral Med Oral Pathol Oral Radiol. 2014;118:573-8.

59. Yuasa K, Kawazu T, Morita M, Uehara S, Kunitake N, Kanda S. A new, simple method of making a spacer in interstitial brachytherapy for mobile tongue cancer. Oral Surg Oral Med Oral Pathol Oral Radiol Endod. 2000:89:519-21.

60. Bodard A, Racadot S, Salino S, Pommier P, Zrounba P, Montbarbon X. A new, simple maxillary-sparing tongue depressor for external mandibular radiotherapy: a case report. Head Neck. 2009;31:1528-30. 
61. Goel A, Tripathi A, Chand P, Singh SV, Pant MC, Nagar A. Use of positioning stents in lingual carcinoma patients subjected to radiotherapy. Int J Prosthodont. 2010;23:450-2.

62. Liu XQ, Luo W, Lin SR, Liu MZ. Placement repeatability of individual oral stent used in radiotherapy of nasopharyngeal carcinoma. Ai Zheng. 2009;28:1103-7.

Submit your next manuscript to BioMed Central and we will help you at every step:

- We accept pre-submission inquiries

- Our selector tool helps you to find the most relevant journal

- We provide round the clock customer support

- Convenient online submission

- Thorough peer review

- Inclusion in PubMed and all major indexing services

- Maximum visibility for your research

Submit your manuscript at www.biomedcentral.com/submit 